Research Article

\title{
Improvement of CT Target Scanning Quality for Pulmonary Nodules by PDCA Management Method
}

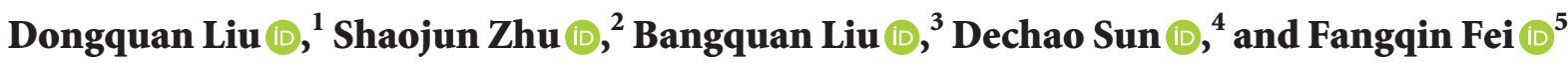 \\ ${ }^{1}$ Radiology Department, Ninghai First Hospital Medicare and Health Group, Ningbo, China \\ ${ }^{2}$ College of Information Engineering, Huzhou University, Huzhou, China \\ ${ }^{3}$ College of Digital Technology and Engineering, Ningbo University of Finance \& Economics, Ningbo, China \\ ${ }^{4}$ College of Electronics and Computer, Zhejiang Wanli University, Ningbo, China \\ ${ }^{5}$ Department of Nursing, The First People's Hospital of Huzhou, Huzhou, Zhejiang, China \\ Correspondence should be addressed to Fangqin Fei; feifangqin@139.com
}

Received 15 December 2020; Revised 6 February 2021; Accepted 6 March 2021; Published 19 March 2021

Academic Editor: Chonghui Zhang

Copyright ( 2021 Dongquan Liu et al. This is an open access article distributed under the Creative Commons Attribution License, which permits unrestricted use, distribution, and reproduction in any medium, provided the original work is properly cited.

\begin{abstract}
High CT image quality is an important guarantee for doctors to correctly diagnose pulmonary nodules. The aim of this study was to explore the application value of PDCA management method in improving the quality of CT target scanning for pulmonary nodules. We identified 480 patients' CT image with at least one pulmonary nodule admitted in Ninghai First hospital from September 1st, 2018, to April 30th, 2019. 240 CT images are carried out by the conventional target scanning method, and we analyzed the reasons for the low quality of some CT target scanning images of pulmonary nodules in the radiology department of our hospital. We established a new process of CT target scanning for pulmonary nodules based on the PDCA method and then tested 240 patients who were checked after January 1st, 2019. The excellent rate of CT target scanning image of pulmonary nodules in our department increased from $60.0 \%$ to more than $90.0 \%$. The patients' satisfaction with the examination was significantly higher than that without the implementation of PDCA management. The research result indicated that the process of CT target scanning image, postprocessing reconstruction, and numerical measurement of pulmonary nodules can be improved by standardized PDCA cycle, which benefits effectively improving the theoretical and operational skills of radiologists and significantly improving the image quality rate of CT target scanning of pulmonary nodules.
\end{abstract}

\section{Introduction}

Delivering improvements in the quality and safety of clinical diagnosis of pulmonary nodules remain an international challenge [1]. In recent years, quality improvement (QI) methods such as plan-do-check-act (PDCA) cycles [2] have been used in an attempt to drive such improvements. CT target scanning is a key process during clinical diagnosis of pulmonary nodules, and the image quality of CT target scanning of pulmonary nodules is one of the major factors affecting the radiologist's judgment of patients' condition and directly related to the doctor's clinical treatment and patient's rehabilitation [3]. CT target scanning of pulmonary nodules includes the following steps: scanning appointment process, saving and utilization of scanning results, operation specification of doctors in the diagnosis group, respiratory training of patients, and setting of scanning range, which involves the cooperation of registrants, technicians, diagnostic doctors, and patients at various levels [4]. Key components of the imaging process, such as patient scheduling and protocol selection, must occur before image generation, diagnostic interpretation, and report generation can be performed [5-7].

PDCA management method ensures the effect and quality of management by formulating activity methods and steps strictly [8-10]. At present, lung cancer is one of the malignant tumors that endanger human life and health. Its morbidity and mortality are at the top of the list [11]. According to the statistical analysis of cancer epidemiology in 2013, the 5-year survival rate of lung cancer is only $15 \%$ 
[12]. The survival rate of lung cancer can be significantly improved by surgical resection in time. Therefore, early diagnosis of lung cancer can improve the survival rate of patients and reduce the rate of nodule thoracotomy with lung benign [13].

The PDCA management and the statistical methods $[14,15]$ are always used to control the occurrence of the problems by analyzing the problems and the causes of the problems [16]. With the development of multislice spiral CT technology and the rapid development of scanning technology in lung cancer screening, the detection rate of pulmonary nodules has significantly increased. However, the focus of pulmonary nodule is usually small, and conventional scanning cannot clearly show the morphological features of the focus. Some phenomena increase the rate of misdiagnosis, such as volume effect after calcification of nodules and solid nodules presented as ground glass nodules. The CT target scan of pulmonary nodules can clearly show the signs of vacuole, lobulation, air bronchus, and margin $[17,18]$.

The purpose of our study was to apply the advantages of PDCA cycle management to the quality control management of CT target scanning of pulmonary nodule, which improves the image quality significantly.

\section{Materials and Methods}

2.1. Materials. The prospective study was approved by the ethical committee of Ninghai First Hospital. In this study, we implemented PDCA management method on January 1, 2019, and selected 60 patients' image of CT target scanning of pulmonary nodules per month from September 1st, 2018, to April 30th, 2019. There was no significant statistical difference between the selected data $(P<0.05)$, and the results were comparable.

2.2. Methods. Before implementing the PDCA management method, the routine method is used to manage CT target scanning of pulmonary nodules; since January 2019, the PDCA circulation method is used to manage it and the PDCA project improvement and implementation team are established. All the staff members of the department participated in the team. The director of the department was appointed as the team leader and responsible for the implementation, training, and supervision of the members of the team. The group meeting is held every week.

2.2.1. Planning $(P)$. We established a PDCA project improvement implementation team with department director as the leader and organized all members of the department to brainstorm the reasons for the poor image quality of CT target scanning part of pulmonary nodules, the nonuniform standard of image postprocessing and reconstruction, and the nonstandard numerical measurement. The fishbone diagram of poor quality of CT target scan of pulmonary nodules is shown in Figure 1, and the detail plans are shown in Table 1.
2.2.2. Do (D). The improvement measures for the noncompliance with the diagnostic specifications (the first reason shown in Table 1) are as follows:

(1) The director of the department organizes all the staff members to study the "CT scan specification of pulmonary nodules" and "imaging diagnosis specification of pulmonary nodules" regularly.

(2) According to the standard, we hold a seminar on the improvement of CT target scanning image of pulmonary nodules and put forward the improving measures and that can be used to solve existing problems on CT target scanning of pulmonary nodules, as follows:

(i) In order to improve the problem of nonstandard reconstruction image caused by the unreasonable FOV setting of thinning image, the scanning technician selects the upper and lower $+3 \mathrm{~cm}$ nodules according to the upper and lower ranges of the specifications, and one lung field and half mediastinum are selected for thinning in the left and right ranges. The reconstructed image was not standard due to the unreasonable FOV setting of thinning image.

(ii) The measures to strengthen the management of scanning plan to improve the problem caused by wrong position selection are as follows: on the day of appointment scanning, the registration personnel shall fill in the basic information of the patient and send it to the doctor of the diagnosis group to mark the location of the nodule; the scanning plan sheet shall be transferred to the CT operation platform for storage; on the day of scanning, the technician shall determine the location of the nodule scanning according to the location marked on the plan sheet and carry out accurate scanning. The lateral position shall be adopted for the CT target scanning of the pulmonary nodule according to the location of the nodule. According to the location of the nodule, the position can be adjusted to recline, supine, and prone so that the nodule is located at the center of the radiation field at the top of the chest.

(iii) The following measures are taken to solve the problem of blur artifacts caused by poor breath holding: the simple and practical method is adopted so that the patients can carry out breathing training in an understanding way, and it can be demonstrated on the spot, establishing the corresponding dialect training mechanism for county hospital, the voice prompts of inspiratory breath holding operation added to the scanning console, and some certain time inspiratory live demonstration for elderly patients; respiratory training was conducted in the scanning interval of the last patient for improving scanning efficiency. 


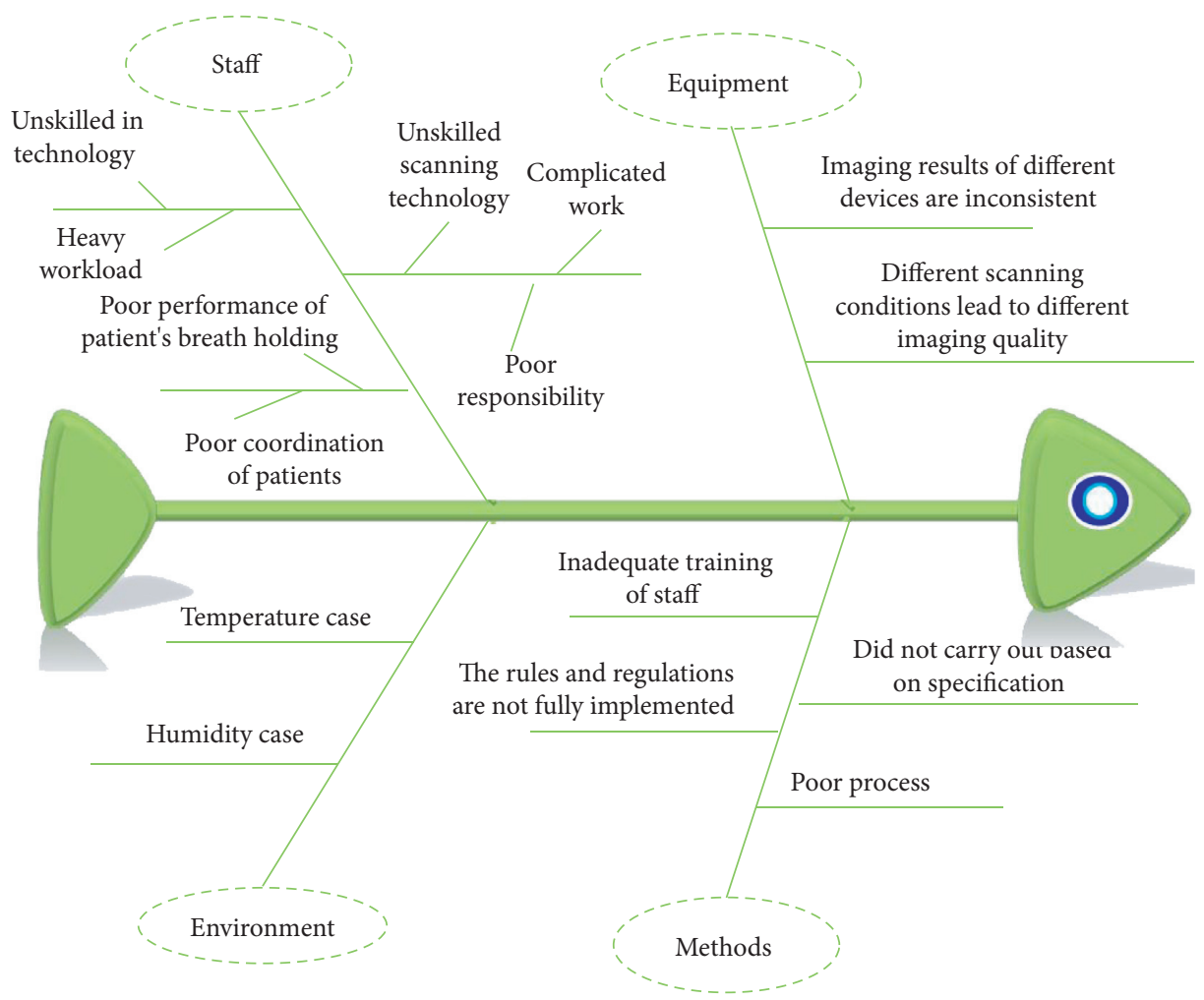

FIGURE 1: Fishbone diagram of poor quality of CT target scan of pulmonary nodules.

TABLE 1: Improvement planning.

\begin{tabular}{|c|c|c|c|c|c|}
\hline Why & What & How & When & Where & Who \\
\hline \multirow{3}{*}{$\begin{array}{l}\text { Implementation is not } \\
\text { in accordance with } \\
\text { specifications }\end{array}$} & \multirow{3}{*}{$\begin{array}{l}\text { Scanning and } \\
\text { reconstruction according to } \\
\text { CT scanning standard of } \\
\text { pulmonary nodules }\end{array}$} & $\begin{array}{l}\text { Learning CT scan standard of } \\
\text { pulmonary nodules }\end{array}$ & 2018.9-2018.10 & $\begin{array}{l}\text { Radiology } \\
\text { classroom }\end{array}$ & All staff \\
\hline & & $\begin{array}{c}\text { Discuss the problems of CT } \\
\text { target scanning of pulmonary } \\
\text { nodules and propose } \\
\text { improvement measures }\end{array}$ & 2018.9-2018.10 & $\begin{array}{l}\text { Radiology } \\
\text { classroom }\end{array}$ & All staff \\
\hline & & $\begin{array}{l}\text { Checking the theoretical } \\
\text { knowledge of staff and } \\
\text { implementation of CT scan } \\
\text { standard for pulmonary nodules }\end{array}$ & 2018.9-2018.10 & $\begin{array}{l}\text { Radiology } \\
\text { classroom }\end{array}$ & All staff \\
\hline \multirow{3}{*}{ Poor process } & \multirow{3}{*}{$\begin{array}{l}\text { Improve the process of } \\
\text { appointment, scanning, and } \\
\text { reconstruction }\end{array}$} & $\begin{array}{c}\text { Asking about routine lung } \\
\text { scanning results when booking }\end{array}$ & 2018.9-2018.12 & $\begin{array}{l}\text { Booking } \\
\text { windows }\end{array}$ & Registrars \\
\hline & & $\begin{array}{c}\text { Technician scans according to } \\
\text { standard process }\end{array}$ & 2018.9-2018.12 & $\begin{array}{l}\text { Toshiba CT } \\
\text { scan console }\end{array}$ & $\begin{array}{l}\text { Scanning } \\
\text { technician }\end{array}$ \\
\hline & & $\begin{array}{l}\text { The diagnosis doctor } \\
\text { reconstructs the image } \\
\text { according to the process of } \\
\text { image reconstruction }\end{array}$ & 2018.9-2018.12 & $\begin{array}{l}\text { The } \\
\text { reconstruct } \\
\text { computer }\end{array}$ & Diagnostician \\
\hline \multirow{2}{*}{$\begin{array}{l}\text { Unskilled } \\
\text { reconstruction } \\
\text { technology }\end{array}$} & \multirow{2}{*}{$\begin{array}{l}\text { Reconstruction technology } \\
\text { training }\end{array}$} & $\begin{array}{l}\text { One to one training for senior } \\
\text { doctors and junior doctors }\end{array}$ & 2018.9-2018.10 & $\begin{array}{l}\text { Radiology } \\
\text { classroom }\end{array}$ & Senior doctors \\
\hline & & $\begin{array}{l}\text { Check the technical ability of } \\
\text { scanning image reconstruction }\end{array}$ & 2018.9-10 & $\begin{array}{l}\text { Rebuild } \\
\text { console }\end{array}$ & $\begin{array}{l}\text { Department } \\
\text { director }\end{array}$ \\
\hline
\end{tabular}

(iv) The unreasonable improvement measures for the measurement of nodule diameter surface are as follows: measure the maximum diameter and its vertical diameter at the maximum level of transverse section, and calculate the average diameter; if there is postprocessing, measure the maximum diameter and its vertical diameter at the second large section on MPR and calculate the average value. We measure them on $\mathrm{fc} 52$ with a thickness of $3 \mathrm{~mm}$ for effect comparison. 
(v) In order to solve the problem of irregular measurement of CT value of nodule, the CT value was measured on $\mathrm{fc} 03$, superimposed with $1 \mathrm{~mm}$ slice thickness image, and the CT value of lung background was measured for comparison.

(vi) In order to solve the problem of image distortion caused by MIP or MINP reconstruction, we unify the image and select the average menu for reconstruction.

The measures for testing the theoretical knowledge and CT scanning procedures of pulmonary nodules are as follows:

(i) Using "Ding Ding" app to check theoretical knowledge.

(ii) Detecting the scanning image quality after the improvement measures, and trace each nonstandard image to the responsible employee.

(iii) Retraining and assessment of unqualified employees.

The corresponding measures taken due to poor process (the second reason shown in Table 1) are as follows: improve the appointment process of CT target scanning of pulmonary nodule:

(i) Improve the appointment process of CT target scanning of pulmonary nodule: if the routine CT is performed in our hospital, the CT target scanning of pulmonary nodule can be performed directly; if the routine CT is performed in the external hospital, the CT target scanning of pulmonary nodule can also be performed in our department with the CT film and report sheet; if only the chest plain film is performed, the CT target scanning of pulmonary nodule cannot be performed in our department, and the patient should be examined by routine CT scanning before deciding whether to have a CT target scanning.

(ii) Attach the flow chart of CT target scanning (shown in Figure 2) to the box where the target scanning plan is stored, and the technician should process it according to the CT target scanning flow of pulmonary nodule strictly.

(iii) Attach the flow chart of CT target image reconstruction of pulmonary nodules (shown in Figure 3) on the table of the image-reconstruction computer where the target scanning plan is stored, and the diagnoses should reconstruct it according to the reconstruction procedure.

For problem of the unskilled technician (the third reason shown in Table 1), the senior doctors will conduct one-toone guidance and training for the junior doctors, and the regular assessment will be conducted after the training.

2.2.3. Check $(C)$. When they viewed the CT images, the readers were asked to make a diagnosis, evaluate the quality of CT findings, and assign scores using a 100-point score as follows:
(1) Each CT image was subjectively evaluated and graded using a 100-point score, and the detailed scoring items are as follows:

(i) Scanning position selection (10 points).

(ii) Respiratory motion artifact (20 points).

(iii) Scanning range (10 points).

(iv) Thinning image FOV (10 points).

(v) Measurement of nodule diameter and surface (20 points).

(vi) Measurement of nodule CT value + measurement of lung background CT value (20 points).

(vii) Pulmonary nodule reconstruction mode (5 points).

(viii) Image enlargement and filling (5 points).

(2) Diagnostic confidence: “90-100" indicated excellent, and " $80-90$ " indicated full good.

\subsubsection{Action (A). The actions are as follows:}

(i) According to the norms of pulmonary nodule scanning and diagnosis, the technician scans the pulmonary nodule to narrow the scanning range and POV value, and the diagnostic physician measures the CT value of ground glass nodule during reconstruction.

(ii) We analyze the unqualified target scanning image to find out the problems and improve continuously every month.

(iii) Administrators need to gather the clinical needs and suggestions every quarter, and the team needs to rectify it and feedback in time.

(iv) Holding training in theory and technology for employees every year.

\subsection{Observed Indexes}

2.3.1. Image Excellent Rate. The image quality was evaluated by radiologists from the aspects of noise, artifact, contrast, and resolution. The image excellent rate is given by

$$
r=\frac{m}{n}
$$

where $m$ is the number of high-quality CT scanning image and $n$ is the total number of CT scanning image.

2.3.2. Inspection Time. In this study, we identified patients with at least one pulmonary nodule who came to our hospital. Two sets of images with 480 images were selected the final analysis. The one set images were selected from September 1st, 2018, to December 31th, 2018 (60 images per month), which were performed using routine CT scanning. The other set images were performed under CT target scanning from January 1st, 2019, to April 30th, 2019 (60 images per month). For each month, we evaluate the quality of CT findings and assign scores using the 100-point method, which is introduced in Section 2.2.3. 


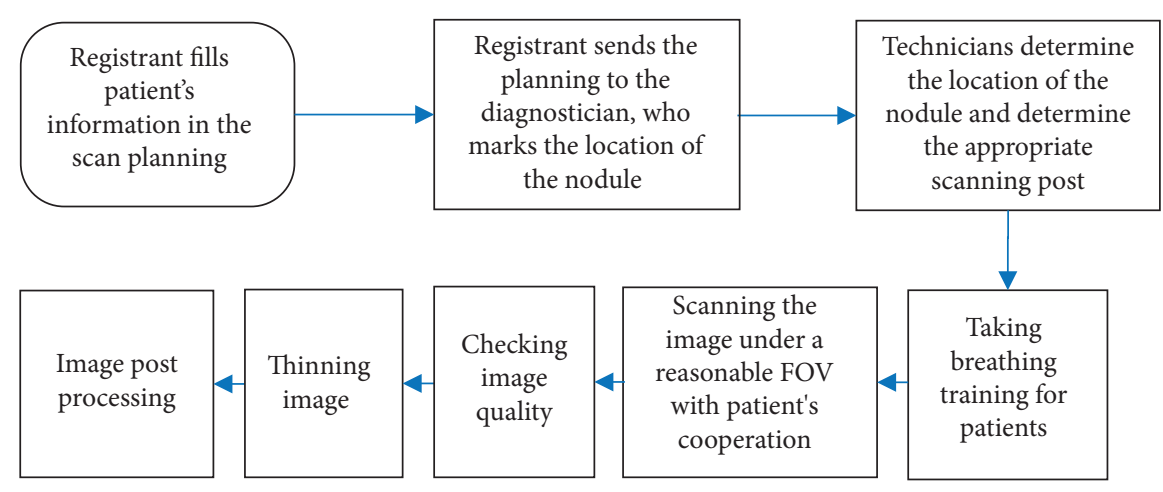

FIgURE 2: Flow chart of CT target scanning of pulmonary nodules.

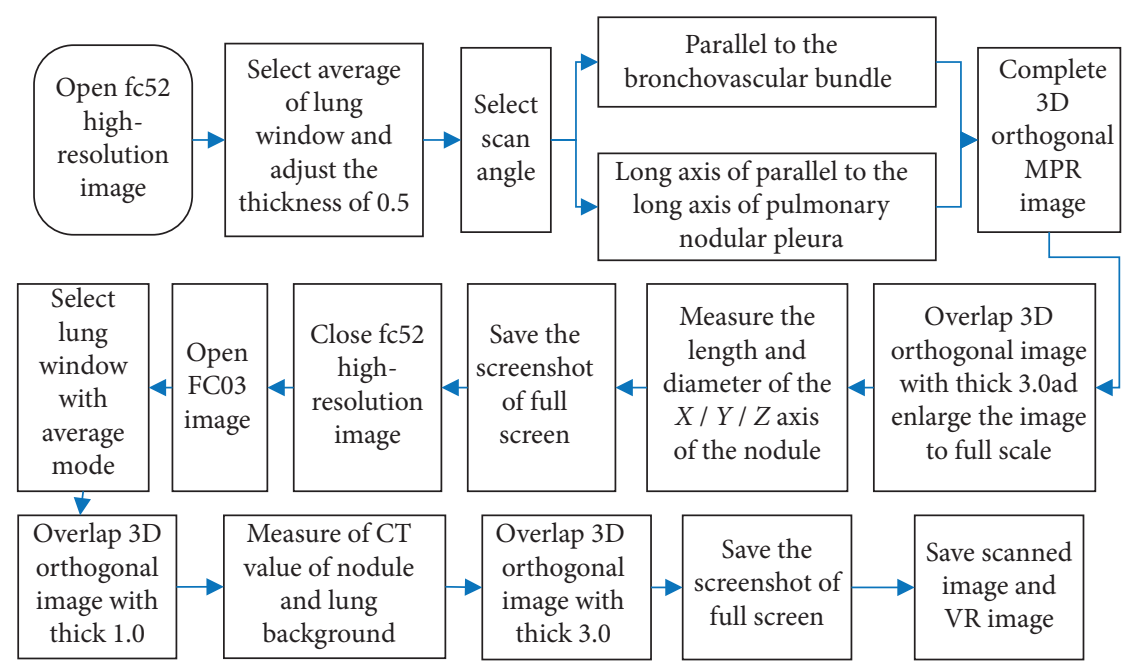

FIgURE 3: Flow chart of CT target image reconstruction of pulmonary nodules.

2.3.3. Patient Satisfaction. The questionnaire survey was used to count the satisfaction of patients with our method. Inclusion criteria were as follows: operation process, service attitude, examination environment, health education, and inspection report and graded using a 20-point score according to a previous report. The total score is 100 points, and the score is directly proportional to the patient's satisfaction.

2.4. Statistical Analysis. Data analysis was performed using the SPSS21.0 software package (SPSS Inc. Chicago, IL, United States). The diagnosis results, treatment recommendation, and diagnosis accuracy were determined using McNemar tests. The Wilcoxon signed-rank test was used to evaluate the image quality scores of the findings and confidence of readers. A $P$ value of less than 0.05 was considered statistically significant.

\section{Results}

3.1. Comparison of Image Excellent Rate. As a result, 480 patients were included the final analysis, and the detail results of CT image quality are shown in Table 2 (all $P<0.05)$.
3.2. Comparison of Inspection Time. Before the implementation of PDCA management, the CT target scan image score of pulmonary nodules is shown in Table 3. From September to December in 2018, the excellent rates of CT images were $60.0 \%, 76.6 \%, 83.3 \%$, and $86.3 \%$, respectively.

The excellent rates of CT images with PDCA management have significantly higher score than without PDCA management. From January to April of 2019, the excellent rates of CT images were 90\%, 95.0\%, 93.3\%, and 96.6\%, respectively (shown in Table 4 ).

3.3. Comparison of Patient Satisfaction. After the implementation of PDCA management, the patients' satisfaction with the examination was significantly higher than that without the implementation of PDCA management, and the $P$ value of less than 0.05 was considered statistically significant; the results are shown in Table 5.

3.4. Comparison of CT Image. Figures 4 and 5 show two representative cases. In cross-sectional images and corresponding MPR images, the edge of nodules and solid internal components were shown more clearly with PDCA management than that without PDCA management. 
TABLe 2: Comparison of excellent rate before and after PDCA methods.

\begin{tabular}{lcccc}
\hline & Noise & Artifact & Contrast & Resolution \\
\hline Without PDCA & $73.16 \pm 5.24$ & $76.42 \pm 4.32$ & $76.16 \pm 5.24$ & $90.16 \pm 5.24$ \\
With PDCA & $93.16 \pm 2.24$ & $94.42 \pm 2.32$ & $92.16 \pm 3.04$ & $94.16 \pm 2.24$ \\
$t$ value & 4.81 & 6.95 & 5.22 & 8.13 \\
$P$ value & $<0.05$ & $<0.05$ & $<0.05$ & $<0.05$ \\
\hline
\end{tabular}

TABLE 3: The excellent rates of CT images without PDCA management.

\begin{tabular}{|c|c|c|c|c|}
\hline Times & 2018.9 & 2018.10 & 2018.11 & 2018.12 \\
\hline Scanning position selection (10 points) & 6 & 7.7 & 8.4 & 8.5 \\
\hline Respiratory motion artifact (20 points) & 11.5 & 15.6 & 17.1 & 17.5 \\
\hline Scanning range (10 points) & 6.3 & 7.8 & 8.4 & 8.7 \\
\hline Thinning image FOV (10 points) & 5.8 & 7.5 & 8.3 & 8.8 \\
\hline Measurement of nodule diameter and surface ( 20 points) & 12.6 & 15.8 & 17.4 & 17.8 \\
\hline Measurement of nodule CT value + measurement ( 20 points) & 12.4 & 15.3 & 17.5 & 18 \\
\hline Pulmonary nodule reconstruction mode ( 5 points) & 2.8 & 3.7 & 4.1 & 4.3 \\
\hline Image enlargement and filling (5 points) & 3.1 & 3.8 & 4.2 & 4.4 \\
\hline Excellent rates & $60.0 \%$ & $76.6 \%$ & $83.3 \%$ & $86.3 \%$ \\
\hline
\end{tabular}

TABLE 4: The excellent rates of CT images with PDCA management.

\begin{tabular}{|c|c|c|c|c|}
\hline Times & 2019.1 & 2019.2 & 2019.3 & 2019.4 \\
\hline Scanning position selection (10 points) & 9.2 & 9.5 & 9.3 & 9.6 \\
\hline Respiratory motion artifact (20 points) & 18.2 & 19.1 & 18.7 & 19.3 \\
\hline Scanning range (10 points) & 9.1 & 9.4 & 9.2 & 9.5 \\
\hline Thinning image FOV (10 points) & 8.9 & 9.3 & 9.3 & 9.4 \\
\hline Measurement of nodule diameter and surface ( 20 points) & 18.1 & 18.8 & 18.9 & 19.2 \\
\hline Measurement of nodule CT value + measurement ( 20 points) & 18.1 & 19.3 & 19.1 & 19.4 \\
\hline Pulmonary nodule reconstruction mode ( 5 points) & 4.1 & 4.7 & 4.6 & 4.8 \\
\hline Image enlargement and filling ( 5 points) & 4.0 & 4.8 & 4.7 & 4.9 \\
\hline Excellent rates & $90.0 \%$ & $95.0 \%$ & $93.3 \%$ & $96.6 \%$ \\
\hline
\end{tabular}

TABLE 5: Comparison of patient satisfaction without and with PDCA methods.

\begin{tabular}{lccccc}
\hline & Operation process & Service attitude & Examination environment & Health education & Inspection report \\
\hline Without PDCA & $15.2 \pm 1.3$ & $15.5 \pm 2.2$ & $14.2 \pm 2.1$ & $13.0 \pm 2.4$ & $15.6 \pm 0.7$ \\
With PDCA & $18.2 \pm 1.4$ & $17.8 \pm 2.3$ & $18.1 \pm 1.7$ & $3.4 \pm 2.4$ & $17.1 \pm 0.6$ \\
$t$ value & 4.16 & 1.76 & 3.42 & 3.52 & 9.85 \\
$P$ value & $<0.05$ & $<0.05$ & $<0.05$ & $<0.05$ & $<0.05$ \\
\hline
\end{tabular}

\section{Discussion}

The PDCA method originates from industry and Walter Shewhart and Edward Deming's articulation of iterative processes which eventually became known as the four stages of PDCA [2]. PDCA cycles offer a supporting mechanism for iterative development and scientific testing of improvements in medical diagnosis management [19]. In clinical examination, the image quality obtained by CT target scanning is often not high, thus affecting the diagnosis of patients [20-22]. However, the excessive and large region CT examination will increase the risk of high cumulative radiation doses. Therefore, it is very important to manage the quality of CT target scan scientifically and effectively. Compared with the standard of technical and diagnostic, the quality of some images of CT target scanning of pulmonary nodules in our department is not high, the standards of image postprocessing and reconstruction are not unified, and the numerical measurement is not standardized.

In this study, PDCA management method was carried out in CT target scanning of pulmonary nodules in our department. In the planning stage $(\mathrm{P})$, we analyzed the main reasons for the low excellent rate of pulmonary nodule image of CT target scanning in our department. The management plans are made to improve the quality of CT target scanning. The medical staff members were trained according to the operation and diagnosis criterion of CT target scanning of pulmonary nodule. In the implementation stage (D), the formulated measures were implemented strictly and all staff members carried out self-inspection actively. In the check 


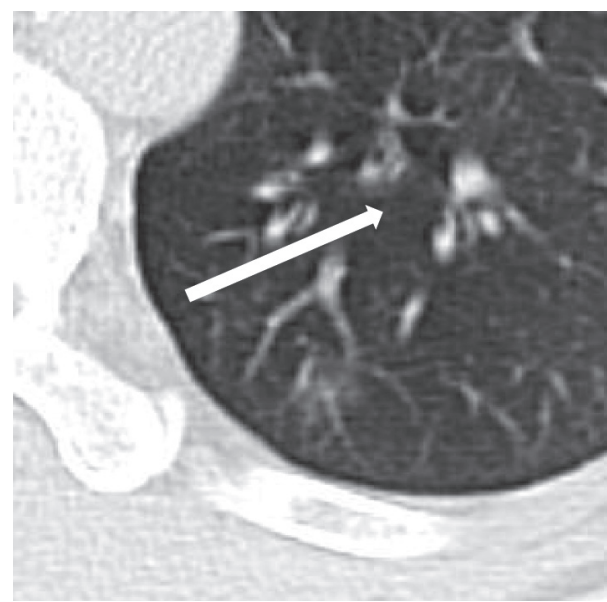

(a)

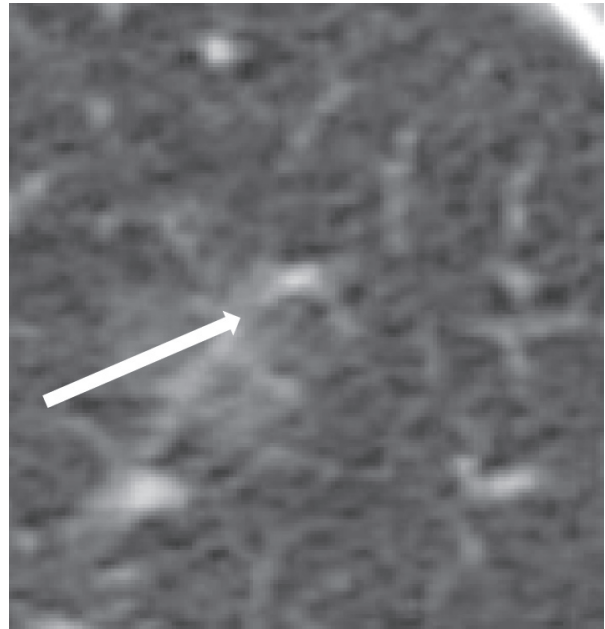

(c)

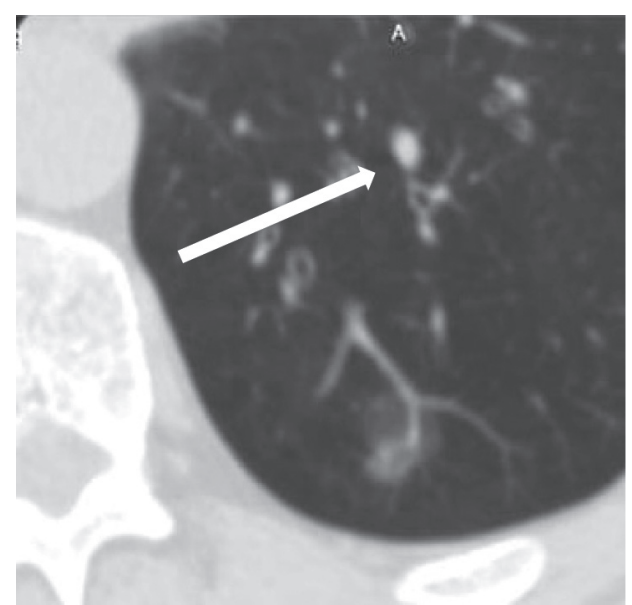

(b)

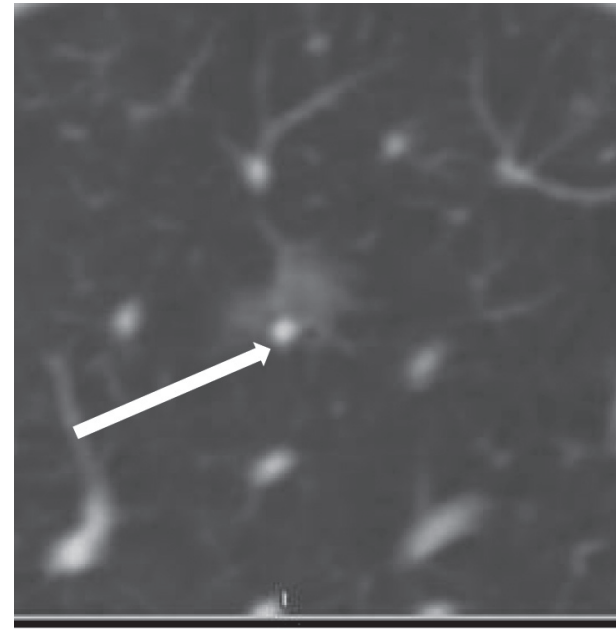

(d)

Figure 4: A 55-year-old male patient. The nodule is located in the dorsal segment of the right lower lobe of the lung: (a) cross-sectional without PDCA management; (b) cross-sectional with PDCA management; (c) coronal without PDCA management; (d) coronal with PDCA management.

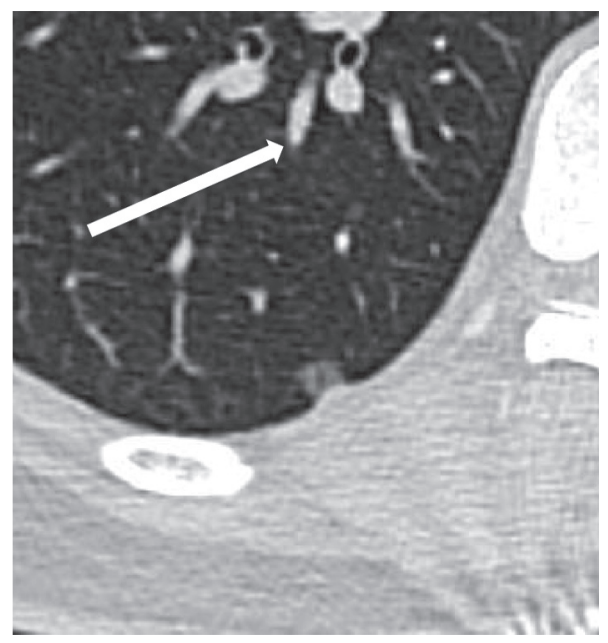

(a)

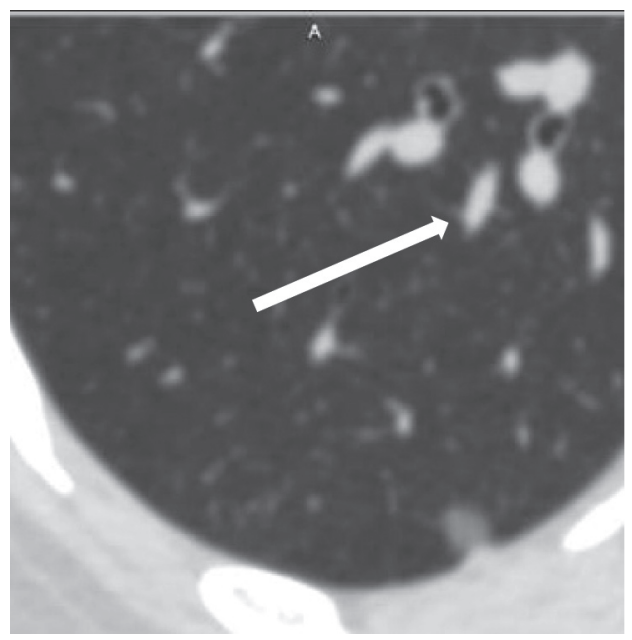

(b)

Figure 5: Continued. 


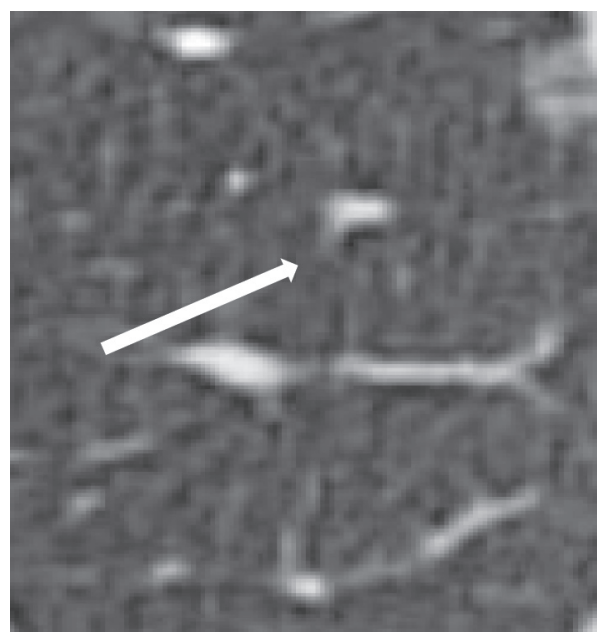

(c)

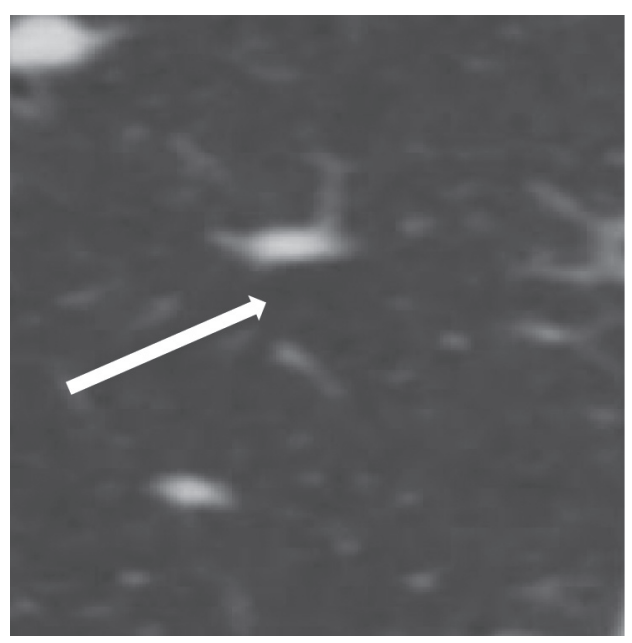

(d)

Figure 5: A 33-year-old male patient. The nodule (arrow) is located in the right lung apex: (a) cross-sectional without PDCA management; (b) cross-sectional with PDCA management; (c) coronal without PDCA management; (d) coronal with PDCA management.

stage (C), the implementation of the measures shall be strictly supervised, and the corresponding operation results shall be spot checked to form the quality table of target scanning of pulmonary nodule. We also summarized and analyzed the existing deficiencies and recorded all rectification measures. In the action stage (A), we analyzed the unqualified target scanning images every month to find out problems and improve them continuously. The problems are found to be continuously improved and incorporated into the next cycle management. Then, we put the new problems into the next cycle management and make a new plan to gradually improve and perfect the procedure.

The results indicated that CT target scanning with PDCA management method can provide a higher image excellent rate compared to without PDCA management method. The application of scanning plan sheet can shorten the examination time and make the localization of scanning nodule more accurate. It can improve the efficiency and quality of the examination process to strengthen the breath holding training of patients according to the CT scan standard of pulmonary nodules. The measurement of the nodules of ground-glass and CT value of lung background can improve the quality of reconstruction image through the use of PDCA cycle to effectively control management of CT target scanning of pulmonary nodule, reduce the radiation dose of patients, optimize the patient's examination process, improve the patient's satisfaction, and achieve good results.

\section{Data Availability}

The simulation data used to support the findings of this study are available from the corresponding author upon request.

\section{Ethical Approval}

This article does not contain any studies with human participants or animals performed by any of the authors.

\section{Disclosure}

Dongquan Liu and Shaojun Zhu should be regarded as the co-first authors.

\section{Conflicts of Interest}

The authors declare that they have no conflicts of interest.

\section{Authors' Contributions}

Dongquan Liu and Shaojun Zhu contributed to the work equally.

\section{Acknowledgments}

This work was supported by the NSF of Zhejiang (Grant nos. LY19F020001 and LQ18F010008), Social Sciences Project of Zhejiang (Grant no. 21NDJC021Z), Science and Technology Plan Project of Zhejiang (Grant no. LGG18F020001), NSF of Ningbo City (Grant nos. 202003N4072, 2017A610115, and 2018A610092), NSF of Huzhou City (Grant no. 2016YZ02), and Peiying Project of Ninghai First Hospital.

\section{References}

[1] M. J. Taylor, C. Mcnicholas, C. Nicolay, A. Darzi, D. Bell, and J. E. Reed, "Systematic review of the application of the plando-study-act method to improve quality in healthcare," $B M J$ Quality \& Safety, vol. 23, no. 4, pp. 290-298, 2014.

[2] W. E. Deming, Out of the Crisis, Massachusetts Institute of Technology Center for Advanced Engineering Study XIII, Cambridge, MA, USA, 1986.

[3] B. Lei, W. Hao, W. Zhu, and K. Yan, "Air-ground rotary scanning imaging system for ground vehicles based on passive infrared detection," IOP Conference Series Materials Science and Engineering, vol. 799, pp. 12-15, 2020.

[4] J. E. Neggers, B. Kwanten, T. Dierckx et al., "Target identification of small molecules using large-scale CRISPR-Cas 
mutagenesis scanning of essential genes," Nature Communications, vol. 9, no. 1, p. 754, 2018.

[5] D. R. Enzmann and D. F. Schomer, "Analysis of radiology business models," Journal of the American College of Radiology, vol. 10, no. 3, pp. 175-180, 2013.

[6] B. V. Wessman, A. K. Moriarity, V. Ametlli, and D. J. Kastan, "Reducing barriers to timely MR imaging scheduling," $R a$ dioGraphics, vol. 34, no. 7, pp. 2064-2070, 2014.

[7] S. Zeng, Y. Hu, and X. Xie, "Q-rung orthopair fuzzy weighted induced logarithmic distance measures and their application in multiple attribute decision making," Engineering Applications of Artificial Intelligence, vol. 100, Article ID 104167, 2021.

[8] G. D. Rubin, "Lung nodule and cancer detection in computed tomography screening," Journal of Thoracic Imaging, vol. 30, no. 2, pp. 130-138, 2015.

[9] C. Zhang, W. Su, S. Zeng, T. Balezentis, and E. HerreraViedma, "A two-stage subgroup decision-making method for processing large-scale information," Expert Systems with Applications, vol. 171, no. 3, Article ID 114586, 2021.

[10] M. K. Bader, S. Palmer, C. Stalcup, and T. Shaver, "Using a focus-PDCA quality improvement model for applying the severe traumatic brain injury guidelines to practice: process and outcomes," The Online Journal of Knowledge Synthesis for Nursing, vol. 9, 2002.

[11] S. M. Lee, C. M. Park, J. M. Goo, H.-J. Lee, J. Y. Wi, and C. H. Kang, "Invasive pulmonary adenocarcinomas versus preinvasive lesions appearing as ground-glass nodules: differentiation by using CT features," Radiology, vol. 268, no. 1, pp. 265-273, 2013.

[12] F. Foley, S. Rajagopalan, S. M. Raghunath et al., "Computeraided nodule assessment and risk yield risk management of adenocarcinoma: the future of imaging?" Seminars in Thoracic and Cardiovascular Surgery, vol. 28, no. 1, pp. 120-126, 2016.

[13] P. Cirujeda, Y. Dicente Cid, H. Muller et al., "A 3D Rieszcovariance texture model for prediction of nodule recurrence in lung CT," IEEE Transactions on Medical Imaging, vol. 35, no. 12 , pp. $2620-2630,2016$.

[14] J. Wang, S. Zeng, and C. Zhang, "Single-valued neutrosophic linguistic logarithmic weighted distance measures and their application to supplier selection of fresh aquatic products," Mathematics, vol. 8, no. 3, p. 439, 2020.

[15] S. Zeng, Y. Hu, T. Balezentis, and D. Streimikiene, "A multicriteria sustainable supplier selection framework based on neutrosophic fuzzy data and entropy weighting," Sustainable Development, vol. 28, no. 5, pp. 1431-1440, 2020.

[16] C. Young, D. Burch, J. Childress, C. Kucharski, E. A. Kazerooni, and M. S. Davenport, "Bacterial contamination CT equipment: use of ATP detection and culture results to target quality improvement," Academic Radiology, vol. 24, no. 8, pp. 923-929, 2017.

[17] E. F. Patz Jr, E. Greco, C. Gatsonis, P. Pinsky, B. S. Kramer, and D. R. Aberle, "Lung cancer incidence and mortality in national lung screening trial participants who underwent lowdose CT prevalence screening: a retrospective cohort analysis of a randomised, multicentre, diagnostic screening trial," The Lancet Oncology, vol. 17, no. 5, pp. 590-599, 2016.

[18] K. A. Khan, P. Nardelli, A. Jaeger, C. O’Shea, P. CantillonMurphy, and M. P. Kennedy, "Navigational bronchoscopy for early lung cancer: a road to therapy," Advances in Therapy, vol. 33, no. 4, p. 580, 2016.

[19] E. B. Stein, P. S. Liu, E. A. Kazerooni, K. Barber, and M. S. Davenport, "Reducing variability in orthogonal reformatted image quality associated with axial long-z-axis CT angiography," AJR: American Journal of Roentgenology, vol. 207, no. 6, pp. 1360-1365, 2016.

[20] Y. Gu, V. Kumar, L. O. Hall et al., "Automated delineation of lung tumors from CT images using a single click ensemble segmentation approach," Pattern Recognition, vol. 46, no. 3, pp. 692-702, 2013.

[21] S. P. Raman, J. L. Schroeder, P. Huang et al., "Preliminary data using computed tomography texture analysis for the classification of hypervascular liver lesions: generation of a predictive model on the basis of quantitative spatial frequency measurements-a work in progress," Journal of Computer Assisted Tomography, vol. 39, no. 3, pp. 383-395, 2015.

[22] D. H. Sterman, T. Keast, L. Rai et al., "High yield of bronchoscopic transparenchymal nodule access real-time imageguided sampling in a novel model of small pulmonary nodules in canines," Chest, vol. 147, no. 3, pp. 700-707, 2015. 